\title{
Mammalian target of rapamycin signaling in diabetic cardiovascular disease
}

\author{
Zhao Zhong Chong ${ }^{1,3}$ and Kenneth Maiese ${ }^{1,2,3^{*}}$
}

\begin{abstract}
Diabetes mellitus currently affects more than 170 million individuals worldwide and is expected to afflict another 200 million individuals in the next 30 years. Complications of diabetes as a result of oxidant stress affect multiple systems throughout the body, but involvement of the cardiovascular system may be one of the most severe in light of the impact upon cardiac and vascular function that can result in rapid morbidity and mortality for individuals. Given these concerns, the signaling pathways of the mammalian target of rapamycin (mTOR) offer exciting prospects for the development of novel therapies for the cardiovascular complications of diabetes. In the cardiovascular and metabolic systems, mTOR and its multi-protein complexes of TORC1 and TORC2 regulate insulin release and signaling, endothelial cell survival and growth, cardiomyocyte proliferation, resistance to $\beta$-cell injury, and cell longevity. Yet, mTOR can, at times, alter insulin signaling and lead to insulin resistance in the cardiovascular system during diabetes mellitus. It is therefore vital to understand the complex relationship mTOR and its downstream pathways hold during metabolic disease in order to develop novel strategies for the complications of diabetes mellitus in the cardiovascular system.
\end{abstract}

Keywords: Akt, AMPK, Cardiac, Diabetes Mellitus, Endothelial, Insulin Receptor Substrate 1, Sirtuin, SIRT1, TORC1, TORC2

\section{Introduction}

The mammalian target of rapamycin (mTOR) is a serine/ threonine protein kinase that controls cellular growth as well as cellular homeostasis [1]. It was isolated in Saccharomyces cerevisiae with the generation of rapamycin-resistant TOR mutants that resulted in the identification of proteins participating in rapamycin toxicity with two homologous genes, namely TOR1 and TOR2 [2]. In eukaryotes, a single gene TOR is present [3]. The protein mTOR is expressed throughout the body and is present in the brain, cardiopulmonary system, gastrointestinal system, immune system, skeletal system, and the reproductive system [4]. The mTOR protein is a $289 \mathrm{kDa}$ protein with multiple domains. The carboxy-terminal acid kinase domain contains a conserved sequence with homology to the catalytic domain of phosphoinositide 3 -kinase (PI 3-K) family [5]. In this domain are the regulatory phosphorylation sites of mTOR that include serine ${ }^{2448}$, serine $e^{2481}$, threonine ${ }^{2446}$, serine $^{2159}$, and threonine $e^{2164}[6-9]$. The C-terminal also contains

\footnotetext{
* Correspondence: wntin75@yahoo.com

${ }^{1}$ Laboratory of Cellular and Molecular Signaling, Newark, NJ , USA

${ }^{2}$ Cancer Institute of New Jersey, New Jersey Health Sciences University, 205

South Orange Avenue, Newark, NJ 07101, USA

Full list of author information is available at the end of the article
}

FKBP12 (FK506 binding protein 12) -rapamycin-associated protein (FRAP), ataxia-telengiectasia (ATM), and transactivation/transformation domain-associated protein domain (FAT) [10]. The FKBP12-rapamycin binding domain (FRB) is adjacent to the FAT domain and is the site of interaction between mTOR and FKBP12 protein bound to rapamycin [11]. The N-terminal of mTOR contains at least a 20 HEAT (Huntingtin, Elongation factor 3, A subunit of Protein phosphatase-2A, and TOR1) repeat [12]. This site provides the necessary binding of the mTOR complex for multimerization with the regulatory-associated protein mTOR (Raptor) or rapamycin-insensitive companion of mTOR (Rictor) [12]. The phosphorylation site serine ${ }^{1261}$ within the HEAT domain can be phosphorylated by insulin signaling both in mTORC1 and mTORC2 through PI 3-K [13]. This leads to an increase in the activity of mTOR and phosphorylation of this site also is required for mTOR serine $^{2481}$ autophosphorylation [13].

\section{Signaling pathways of mTOR}

mTOR can form two multi-protein complexes that consist of mTOR Complex 1 (mTORC1) and mTOR Complex 2 (mTORC2) [1,14]. mTORC1 employs the regulatory-

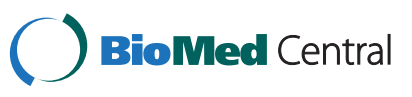

(C) 2012 Chong and Maiese; licensee BioMed Central Ltd. This is an Open Access article distributed under the terms of the Creative Commons Attribution License (http://creativecommons.org/licenses/by/2.0), which permits unrestricted use, distribution, and reproduction in any medium, provided the original work is properly cited. 


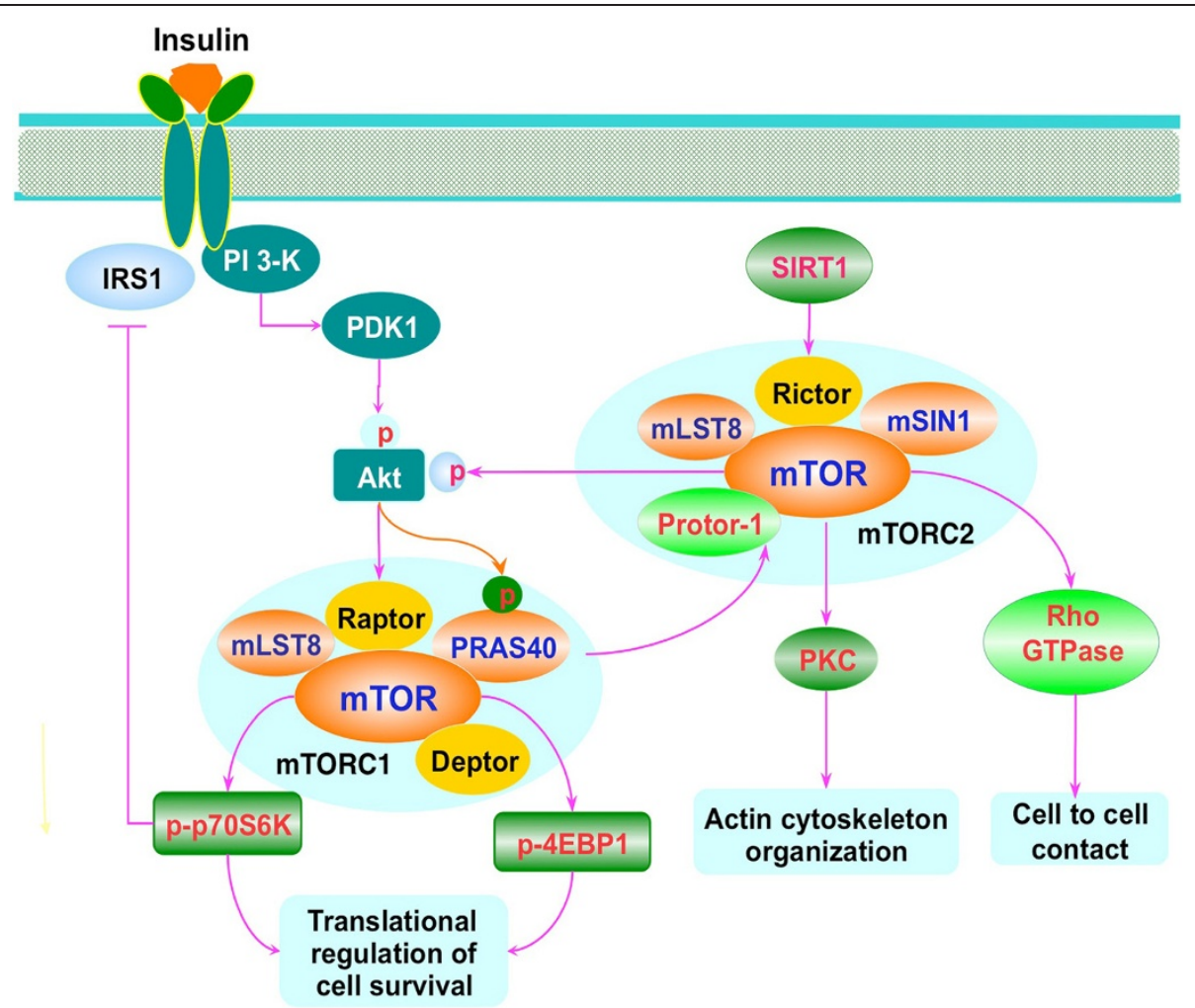

Figure 1 Insulin mammalian target of rapamycin signaling pathways. Insulin activates mTORC1 through phosphoinositide 3 kinase (PI 3-K)/ Akt mediated pathways. mTORC1 consists of the regulatory-associated protein of mTOR (Raptor), the proline rich Akt substrate $40 \mathrm{kDa}$ (PRAS40), the mammalian lethal with Sec13 protein 8 ( $\mathrm{mLST} 8$ ), and the DEP domain-containing mTOR interacting protein (Deptor). Insulin can stimulate PI $3-K$ activation and subsequent recruitment of Akt to the plasma membrane through activation by phosphoinositide dependent kinase 1 (PDK1). Once active, Akt can result in the activation of mTORC1 through a series of signaling pathways. Akt can also directly phosphorylate PRAS40 and reduce its binding to Raptor and release mTORC1 from its suppression by PRAS40. Upon activation, mTORC1 phosphorylates its two major downstream targets p70 ribosome S6 kinase (p70S6K) and eukaryotic initiation factor 4E-binding protein 1 (4EBP1) and mediates cell growth, proliferation, and cell survival. mTOR can lead to inhibitory phosphorylation of the insulin receptor substrate 1 (IRS1). mTORC2 contains Rictor, mTOR, mLST8, Deptor, the mammalian stress-activated protein kinase interacting protein (mSIN1), and protein observed with Rictor-1 (Protor-1). The sirtuin SIRT1 may regulate the transcription of the gene encoding rapamycin insensitive companion of mTOR (Rictor) and promote the activation of mTORC2. mTORC2 regulates actin skeleton organization and cell survival through activating Akt and protein kinase C (PKC). In addition, mTORC2 can activate Rho GTPases and control cell to cell contact via Rho signaling pathways.

associated protein of mTOR (Raptor) as a scaffolding protein which is essential to recruit mTOR substrates to mTORC1 [15]. The other components of mTORC1 are the proline rich Akt substrate $40 \mathrm{kDa}$ (PRAS40), the mammalian lethal with Sec13 protein 8 (mLST8), and the DEP domain-containing mTOR interacting protein (Deptor) $[1,4,16]$. Also known as Akt1s1, PRAS40 can block mTORC1 activity through its association with Raptor $[17,18]$. Insulin can stimulate the phosphorylation of PRAS40 through protein kinase B (Akt) to prevent the inhibition of mTORC1 by PRAS40 [19]. mLST8 may function to maintain insulin signaling through FoxO3 [20] and has recently been associated with extension of lifespan in mice [21]. Deptor expression is inhibited by MTORC1 and mTORC2 $[1,4,16]$. In the absence of Deptor, Akt, mTORC1 and mTORC2 activities are increased, but in some forms of cancer, Deptor expression is necessary for Akt signaling [22] (Figure 1).

The serine/threonine kinase ribosomal protein p70S6K and the eukaryotic initiation factor 4E-binding protein 1 (4EBP1) are two downstream targets of mTORC1. The binding of Raptor to mTOR is necessary for mTOR-catalyzed phosphorylation of 4EBP1. This binding enhances mTOR kinase activity toward p70S6K [23]. In contrast, PRAS40 can competitively inhibit the binding of the mTORC1 substrates p70S6K and 4EBP1 to Raptor. Phosphorylation of p70S6K by mTORC1 promotes mRNA biogenesis, translation of ribosomal proteins, and cell growth [24]. In the hypophosphorylated state, 4EBP1 binds competitively to the translation initiation factor eukaryotic translation initiation factor 4 epsilon (eIF4E) to block translation through eukaryotic translation initiation 
factor 4 gamma (eIF4G), a protein necessary to bring mRNA to the ribosome, by inhibiting contact of eIF4E with 5'- capped mRNAs. Phosphorylation of 4EBP1 by mTORC1 results in the dissociation from eIF4E to allow eIF4G to begin mRNA translation. Insulin has been found to augment phosphorylation of 4EBP1 through mTOR mediated pathways [25].

Unlike mTORC1, mTORC2 does not have Raptor as a component but contains Rictor (Figure 1). However, mTORC2 shares several common components with mTORC1, such as mTOR, mLST8, and Deptor. mTORC2 also associates with the mammalian stress-activated protein kinase interacting protein (mSIN1) and protein observed with Rictor-1 (Protor-1). mTORC2 not only regulates actin cytoskeleton organization [26], but also can control cell size, cell cycle progression [27], and endothelial cell survival and migration [28]. Rictor is relatively insensitive to rapamycin, promotes the activity of mTORC2, and is necessary for insulin-stimulated glucose uptake [29]. Rictor enables mTORC2 to phosphorylate Akt at $\mathrm{Ser}^{473}$ to lead to its activation and to facilitate threonine ${ }^{308}$ phosphorylation by phosphoinositide-dependent kinase 1 (PDK1) [30]. As previously noted, mLST8 is important to maintain the Rictor-mTORC2 interaction along with Rictor phosphorylation of Akt and PKC $[20]$. Alternate splicing can generate at least 5 isoforms for mSIN1 that can respond to different signals, such as insulin, to allow TORC2 to phosphorylate Akt [31]. Rictor and mSIN1 have been shown to stabilize each other to form the structural basis of mTORC2 and are required for Akt phosphorylation [32]. Recently, mTOR has been shown to phosphorylate mSIN1 to prevent its lysosomal degradation [33]. Protor-1 is a Rictor-binding subunit of mTORC2 that does not affect the expression or activity of the other mTORC2 components to phosphorylate Akt or PKC $\alpha$ [34]. Protor-1 may function to activate serum and glucocorticoid induced protein kinase 1 (SGK1) through mTORC2. Loss of Protor-1 in mice leads to a reduction in the hydrophobic motif phosphorylation of SGK1 and its substrate N-Myc downregulated gene 1 in the kidney [35]. Similar to TORC1, TORC2 inhibits Deptor expression. In addition, Deptor can negatively modulate TORC2 [22].

Downstream targets of TORC2 include Akt, protein kinase C (PKC), P-Rex1 and P-Rex2, and Rho GTPases. P-Rex 1 and P-Rex 2 are tied to Rac activation, mTORC2, and cell migration [36]. mTORC2 also phosphorylates PKC $\alpha$ to modulate cytoskeleton remodeling [37], increases Akt activation [30], and affects Rho signaling pathways that control cell - cell contact [38].

\section{Diabetes mellitus and cardiovascular disease}

Diabetes mellitus (DM) is becoming a significant burden to the world healthcare system with more than 170 million individuals affected throughout the globe [39-42]. In the
Unites States alone, it is expected that greater than 20 million individuals in the United States suffer from DM with an additional significant number of individuals that are undiagnosed DM [43], signaling the need for improved healthcare for metabolic disorders $[41,44,45]$. Type 1 insulin-dependent DM is present in approximately 10 percent of all diabetics, is increasing in adolescent minority groups, and leads to complications in the cardiovascular system [46,47]. Patients with Type 1 DM have insulin resistance that is usually characteristic of Type $2 \mathrm{DM}$ and can result in neurological and vascular disease [48,49]. Type 2 noninsulin-dependent DM represents at least 80 percent of all diabetics and represents a progressive deterioration of glucose tolerance with early $\beta$-cell compensation for insulin resistance $[50,51]$. This is followed by progressive decrease in $\beta$ cells mass. Type $2 \mathrm{DM}$ usually occurs in individuals over 40 years of age and is increasing in incidence as a result of changes in human behavior and increased body mass index $[40,44,52-54]$.

Complications of DM and insulin resistance have been closely tied to the release of reactive oxygen species (ROS) and subsequent oxidative stress $[45,55,56]$. The initial period of elevated glucose may increase the presence of potentially protective pathways [57-59], but more prolonged exposure of elevated glucose can lead to ROS generation $[60,61]$ and can be detrimental even if glucose levels are controlled [62]. Hyperglycemia can lead to oxidative stress in the cardiovascular system $[47,63]$. Prolonged periods of elevated glucose is not necessary to lead to vascular oxidative stress injury, since minimal periods of hyperglycemia generate ROS and lead to endothelial cell death [64-66]. Elevated glucose in human endothelial cells also can raise the expression of antioxidants that include superoxide-dismutase, catalase, and glutathione peroxidase, illustrating that vascular cells may attempt to initially negate the effects of oxidant stress injury [67]. In addition, pathways associated with the transcriptional coactivator, peroxisome proliferator activated receptor-gamma coactivator $1 \alpha(\mathrm{PGC}-1 \alpha)$, may provide protection in the cardiovascular system to maintain mitochondrial homeostasis [68]. Other therapeutic regiments that block oxidative stress in the vascular system involve the cytokine erythropoietin $[56,69]$ and growth factors such as insulin growth factor [70]. At the clinical level, DM in the cardiovascular system can result in platelet dysfunction [71], lead to increased mortality with acute coronary syndromes [72], and result in impairments in sympathetic nervous [73].

\section{Diabetes and cell longevity pathways}

Knowledge from clinical studies strongly suggest that acute glucose level changes can trigger oxidative stress during Type 2 DM, suggesting the need for effective and therapeutic interventions during acute and sustained 


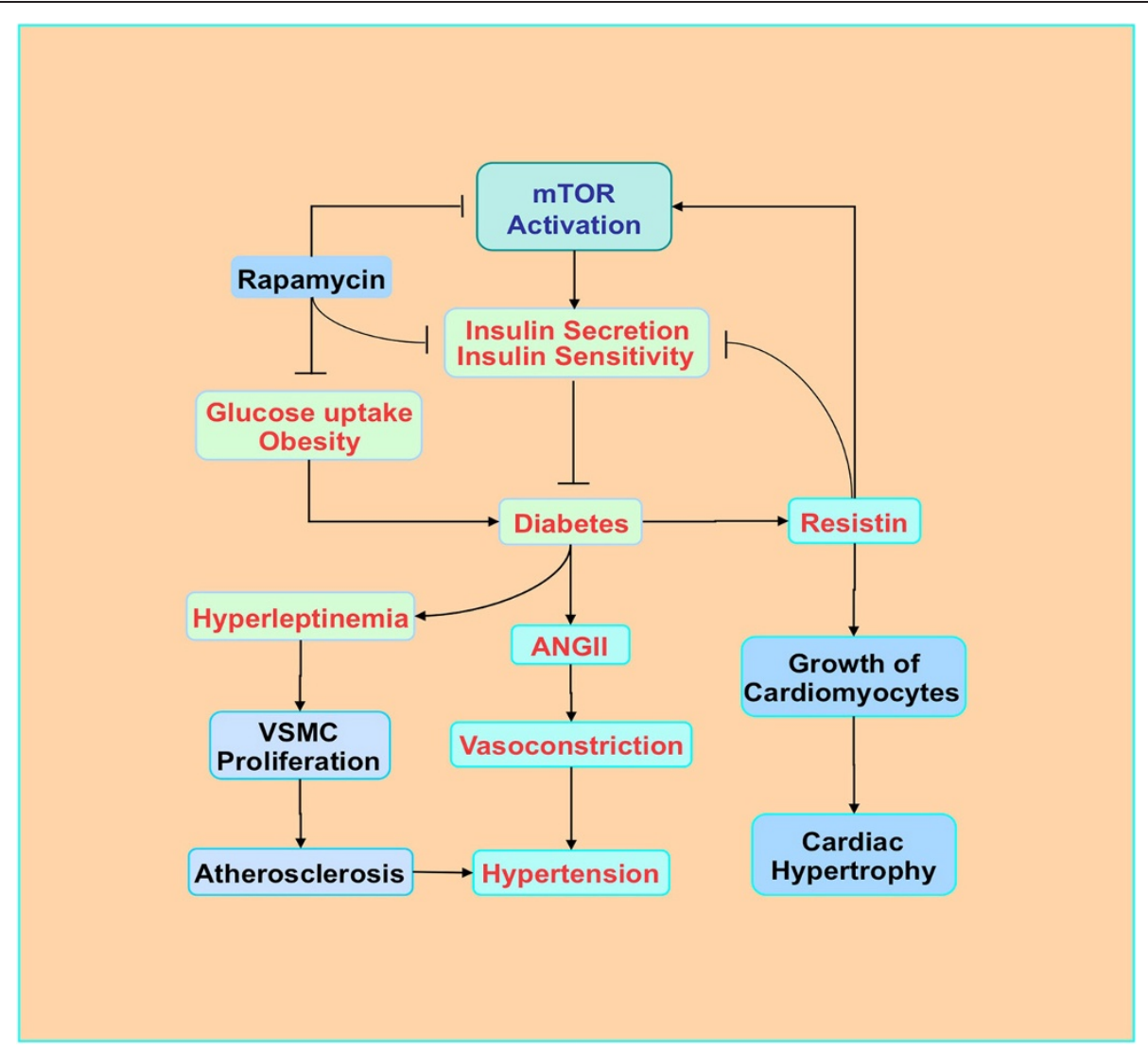

Figure 2 The role of mTOR in diabetic cardiovascular disease. Activation of mTOR promotes the secretion of insulin and increases insulin sensitivity. In contrast, rapamycin reduces insulin sensitivity, reduces glucose uptake and may prevent obesity. Hyperleptinemia can occur with diabetes and activates mTOR, stimulates vascular smooth muscle cell (VSMC) proliferation, and ultimately may contribute to atherosclerosis and hypertension. High glucose and obesity stimulate the production of angiotensin II (ANG II) to result in insulin resistance and elevated vascular tension, contributing to hypertension. Elevated resistin (for resistance to insulin) levels during diabetes can increase insulin resistance and promote mTOR activity to favor the growth of cardiomyocytes and cardiac hypertrophy.

hyperglycemic episodes [74,75]. In this regard. it is interesting to note that diabetic complications that can involve multiple systems of the body including the cardiovascular system also have been closely linked with pathways of cell longevity and mTOR signaling. In studies that have examined caloric restriction in male mice, genes with the greatest statistical change following caloric restriction involved those linked to the sirtuin pathways and the inhibition of mTOR signaling [76]. Sirtuins, such as SIRT1, have been shown to be protective in the cardiovascular system during DM [77-80]. SIRT1 activation can prevent endothelial senescence during hyperglycemia [81] reduce endothelial atherosclerotic lesions during elevated lipid states [82], and prevent oxidative stress injury in cardiomyocytes through p53 deacetylation and the expression of manganese superoxide dismutase (MnSOD) [83,84]. SIRT1 blocks endothelial cell apoptosis during experimental diabetes $[65,85]$, and prevents age-related cardiac hypertrophy, apoptosis, cardiac dysfunction, and senescence marker expression in mice [86].
SIRT1 appears to be closely linked to mTOR signaling during DM. Recent work has shown that hepatic SIRT1 deficiency yields hepatic glucose overproduction, hyperglycemia, products of oxidative stress, and inhibition of the gene encoding Rictor that lead to impaired TORC2 and Akt signaling [87]. In addition, under some conditions of cell stress such as nutrient loss in other cell systems, SIRT1 may have an inverse relationship with mTOR activity [88]. Furthermore, other studies have demonstrated that inhibition of mTOR signaling can extend lifespan in mammals $[21,89]$, provide resistance to the loss of insulin signaling [90], and prevent age -related weight gain that can generate strain upon the cardiovascular system [91].

\section{mTOR signaling in diabetic cardiovascular disease}

Intact mTOR pathways may be vital for proper insulin signaling in diabetics (Figure 2 . In pancreatic $\beta$-cells, loss of mTOR signaling with p70S6K has been shown to lead to hypoinsulinemia, glucose intolerance, insulin insensitivity to glucose secretion, and a decrease in $\beta$-cell size [92]. 
Furthermore, increased phosphorylation of p70S6K and $4 \mathrm{EBP} 1$ in pancreatic $\beta$-cells results in mice improved insulin secretion and resistance to $\beta$-cell streptozotocin toxicity and obesity [93]. In contrast, mTOR inhibition during rapamycin application leads to insulin resistance, reduces $\beta$-cell function and mass, limits insulin secretion, and results in DM [94]. Although inhibition of mTOR with rapamycin reduces food intake and prevents fat-diet induced obesity in mice, rapamycin administration attenuates glucose uptake and metabolism in skeletal muscle through prevention of insulin generated Akt activation and alteration in the translocation of glucose transporters to the plasma membrane [95].

It is important to note that although insulin is a potent activator of mTOR through Akt regulatory pathways, mTOR may have a negative feedback loop and led to glucose intolerance through inhibition of the insulin receptor substrate 1 (IRS1). For example, mTOR signaling through the tuberous sclerosis complex (TSC1, hamartin/ TSC2, tuberin) can inactivate IRS and phosphorylate p70S6K to block IRS1 activity by direct phosphorylation [96]. As a result, activation of the mTOR pathway in the cardiovascular system may lead to poor insulin signaling and insulin resistance. In experiments with high fat fed obese rats, activity of the mTOR pathway is elevated in skeletal muscle and leads to inhibitory phosphorylation of IRS1, impaired Akt signaling, and insulin resistance [97]. Increased consumption of high fat diets also activates the renin-angiotensin-aldosterone system with increased circulating angiotensin II (ANG II). In aortic endothelial cells, ANG II can stimulate mTOR and p70S6K activation that phosphorylates IRS1 and inhibits endothelial nitric oxide synthase that not only may contribute to insulin resistance but also to vasoconstriction and hypertension [98].

Cardiac protection during DM may rely upon the activation of AMP activated protein kinase (AMPK). AMPK can phosphorylate tuberin (TSC2) and inhibit mTORC1 [99]. Increased AMPK activation has been shown to reduce myocardial infarct size during models of DM [100]. In addition, loss of AMPK activity can increase insulin resistance in skeletal muscle [101]. Down-regulation of the AMPK pathway also may be detrimental to cardiac tissue. For example, the liver kinase B1 (LKB1) can regulate the activation of AMPK via phosphorylation [102]. Loss of LKB1 has been shown to impair cardiac function during either aerobic or ischemic conditions [103], illustrating the importance of AMPK signaling in the mTOR pathway for the cardiovascular system.

Cardiac hypertrophy also may be a product of increased mTOR activity during diabetes (Figure 2). The signaling molecule resistin (for resistance to insulin) has enhanced circulating levels during obesity and diabetes. In addition, application of anti-resistin antibodies improves blood glucose and insulin efficacy in murine models of diet-induced obesity [104]. Resistin has recently been shown in rat ventricular myocytes to inhibit AMPK activity, activate TCS2 of the mTOR pathway, and increase cell size leading to cardiac hypertrophy [105]. Resistin also phosphorylates IRS1 through mTOR to promote insulin resistance [105].

Cardiovascular disease also may be mediated through hyperleptinemia and the activation of mTOR (Figure 2). Hyperleptinemia can co-exist with DM and has been shown to enhance mTOR activity and stimulate vascular smooth muscle cell proliferation [106]. Complications of drug eluting stents coated with the mTOR inhibitor rapamycin that lead to re-stenosis in patients with DM are believed to occur as a result of concurrent hyperleptinemia that can override the mTOR inhibition of rapamycin in these patients. Interestingly in patients with metabolic syndrome that have elevated insulin levels, lymphocytes of these patients have reduced expression of mTOR that may contribute to increased risk for vascular thrombosis [107]. Furthermore, exercise in obese rats increased the ability of insulin to phosphorylate Akt and led to increases in Raptor, p70S6K, and 4EBP1 phosphorylation, suggesting that under some circumstances a balanced level of mTOR pathway activity may be beneficial for patients with DM [108].

\section{Conclusions}

Metabolic cardiovascular disease is closely regulated through the mTOR signaling pathways. The mTOR multi-protein complexes of TORC1 and TORC2 can oversee insulin signaling, vascular survival, and cardiomyocyte growth. Downstream, pathways tied to mTOR pathway components, such as p70S6K and 4EBP1, can regulate insulin secretion and resistance to $\beta$-cell injury that ultimately affect diabetic complications in the cardiovascular system. Interestingly, new studies have linked mTOR signaling to the cell longevity pathways of SIRT1 that can also provide robust cardiovascular protection against models of experimental diabetes.

Although mTOR can be beneficial to promote insulin signaling through regulatory pathways that involve Akt, a careful modulation of mTOR activity may be necessary for the treatment of cardiovascular complications during DM. Increased physical activity, which is a requisite therapy for diabetics, can promote phosphorylation of $\mathrm{mTORC1}$ components Raptor, p70S6K, and 4EBP1 to assist with insulin signaling. Yet, mTOR may have a negative feedback loop and can inactivate IRS that may lead to poor insulin signaling and insulin resistance in the cardiovascular system. In addition, mTOR signaling during DM may result in cardiac hypertrophy, promote some of the ill effects of hyperleptinemia, and further diabetic retinopathy [109] given the ability of mTOR to promote angiogenesis $[1,110]$. Activation of pathways of mTOR also may promote tumor growth $[38,111]$ and increase the activation of inflammatory cell pathways [112-116] that may negatively impact 
the cardiovascular system. It therefore becomes crucial to elucidate the varied pathways of mTOR signaling and the role that these pathways have upon the metabolic and cardiovascular systems for the effective and safe development of promising therapies that can be targeted against diabetic complications in the cardiovascular system.

\section{Abbreviations}

AMPK: AMP activated protein kinase; ANG II: angiotensin II;

ATM: ataxia-telengiectasia; Deptor: DEP domain-containing mTOR interacting protein; DM: diabetes mellitus; 4EBP1: eukaryotic initiation factor 4E-binding protein 1; elF4E: eukaryotic translation initiation factor 4 epsilon; elF4G: eukaryotic translation initiation factor 4 gamma; FRAP: FKBP12 (FK506 binding protein 12) -rapamycin-associated protein; FRB: FKBP12-rapamycin binding domain; IRS1: insulin receptor substrate 1; LKB1: liver kinase B1; mLST8: mammalian lethal with Sec13 protein 8; mSIN1: mammalian stress-activated protein kinase interacting protein; mTOR: mammalian target of rapamycin; MnSOD: manganese superoxide dismutase; mTORC1: mTOR Complex 1; mTORC2: mTOR Complex 2; $\mathrm{NAD}^{+}$: nicotinamide adenine dinucleotide; PGC-1a: peroxisome proliferator activated receptor-gamma coactivator 1a; PI 3-K: phosphoinositide 3 -kinase; PDK1: phosphoinositide-dependent kinase 1; PKC: protein kinase C; Akt: protein kinase B; PRAS40: proline rich Akt substrate 40 kDa; Rictor: rapamycin-insensitive companion of mTOR; ROS: reactive oxygen species; Raptor: regulatory-associated protein $\mathrm{mTOR}$; SGK1: serum and glucocorticoid induced protein kinase 1; TSC1 hamartin/TSC2, tuberin: tuberous sclerosis complex.

\section{Competing interests}

The authors have no competing interests.

\section{Authors' contributions}

ZZC and KM drafted the manuscript. ZZC and KM completed the final versions of the manuscript with the incorporation of figures and tables. All authors read and approved the final manuscript.

\section{Acknowledgments}

This research was supported by the following grants to Kenneth Maiese: American Diabetes Association, American Heart Association (National), Bugher Foundation Award, LEARN Foundation Award, NIH NIEHS, NIH NIA, $\mathrm{NIH}$ NINDS, and NIH ARRA.

\section{Author details}

'Laboratory of Cellular and Molecular Signaling, Newark, NJ , USA. ${ }^{2}$ Cancer Institute of New Jersey, New Jersey Health Sciences University, 205 South Orange Avenue, Newark, NJ 07101, USA. ${ }^{3}$ New Jersey Health Sciences University, Newark, NJ 07101, USA.

Received: 4 April 2012 Accepted: 30 April 2012

Published: 16 July 2012

\section{References}

1. Chong ZZ, Shang YC, Zhang L, Wang S, Maiese K: Mammalian target of rapamycin: hitting the bull's-eye for neurological disorders. Oxid Med Cell Longev 2010, 3:374-391.

2. Heitman J, Mowa NR, Hall MN: Targets for cell cycle arrest by the immunosuppressant rapamycin in yeast. Science 1991, 253:905-909.

3. Weber JD, Gutmann DH: Deconvoluting mTOR biology. Cell Cycle 2012, 11:236-248

4. Hwang SK, Kim HH: The functions of mTOR in ischemic diseases. BMB Rep 2011, 44:506-511.

5. Abraham RT: mTOR as a positive regulator of tumor cell responses to hypoxia. Curr Top Microbiol Immunol 2004, 279:299-319.

6. Ekim B, Magnuson B, Acosta-Jaquez HA, Keller JA, Feener EP, Fingar DC: mTOR Kinase Domain Phosphorylation Promotes mTORC1 Signaling, Cell Growth, and Cell Cycle Progression. Mol Cell Biol 2011, 31:2787-2801.

7. Soliman GA, Acosta-Jaquez HA, Dunlop EA, Ekim B, Maj NE, Tee AR, Fingar DC: mTOR Ser-2481 autophosphorylation monitors mTORC-specific catalytic activity and clarifies rapamycin mechanism of action. J Biol Chem 2010, 285:7866-7879.
8. Reynolds THt, Bodine SC, Lawrence JC Jr: Control of Ser2448 phosphorylation in the mammalian target of rapamycin by insulin and skeletal muscle load. J Biol Chem 2002, 277:17657-17662.

9. Scott PH, Brunn GJ, Kohn AD, Roth RA, Lawrence JC Jr: Evidence of insulin-stimulated phosphorylation and activation of the mammalian target of rapamycin mediated by a protein kinase $B$ signaling pathway. Proc Natl Acad Sci U S A 1998, 95:7772-7777.

10. Takahashi T, Hara K, Inoue H, Kawa Y, Tokunaga C, Hidayat S, Yoshino K, Kuroda Y, Yonezawa K: Carboxyl-terminal region conserved among phosphoinositide-kinase-related kinases is indispensable for mTOR function in vivo and in vitro. Genes Cells 2000, 5:765-775.

11. Chen J, Zheng XF, Brown EJ, Schreiber SL: Identification of an 11-kDa FKBP12-rapamycin-binding domain within the 289-kDa FKBP12-rapamycinassociated protein and characterization of a critical serine residue. Proc Natl Acad Sci U S A 1995, 92:4947-4951.

12. Takahara T, Hara K, Yonezawa K, Sorimachi H, Maeda T: Nutrient-dependent multimerization of the mammalian target of rapamycin through the N-terminal HEAT repeat region. J Biol Chem 2006, 281:28605-28614

13. Acosta-Jaquez HA, Keller JA, Foster KG, Ekim B, Soliman GA, Feener EP, Ballif BA, Fingar DC: Site-specific mTOR phosphorylation promotes mTORC1-mediated signaling and cell growth. Mol Cell Biol 2009, 29:4308-4324.

14. Martin DE, Hall MN: The expanding TOR signaling network. Curr Opin Cell Biol 2005, 17:158-166.

15. Kim DH, Sarbassov DD, Ali SM, King JE, Latek RR, Erdjument-Bromage $H$, Tempst P, Sabatini DM: mTOR interacts with raptor to form a nutrientsensitive complex that signals to the cell growth machinery. Cell 2002, 110:163-175.

16. Benjamin D, Colombi M, Moroni C, Hall MN: Rapamycin passes the torch: a new generation of mTOR inhibitors. Nat Rev Drug Discov 2011, 10:868-880.

17. Wang $H$, Zhang $Q$, Wen $Q$, Zheng Y, Philip L, Jiang H, Lin J, Zheng W: Proline-rich Akt substrate of $40 \mathrm{kDa}$ (PRAS40): a novel downstream target of PI3k/Akt signaling pathway. Cell Signal 2012, 24:17-24.

18. Wang L, Harris TE, Roth RA, Lawrence JC Jr: PRAS40 regulates mTORC1 kinase activity by functioning as a direct inhibitor of substrate binding. J Biol Chem 2007, 282:20036-20044.

19. Sancak Y, Thoreen CC, Peterson TR, Lindquist RA, Kang SA, Spooner E, Carr SA, Sabatini DM: PRAS40 is an insulin-regulated inhibitor of the mTORC1 protein kinase. Mol Cell 2007, 25:903-915.

20. Guertin DA, Stevens DM, Thoreen CC, Burds AA, Kalaany NY, Moffat J, Brown M, Fitzgerald KJ, Sabatini DM: Ablation in mice of the mTORC components raptor, rictor, or $\mathrm{mLST} 8$ reveals that $\mathrm{mTORC2}$ is required for signaling to Akt-FOXO and PKCalpha, but not S6K1. Dev Cell 2006, 11:859-871.

21. Lamming DW, Ye L, Katajisto P, Goncalves MD, Saitoh M, Stevens DM, Davis $J G$, Salmon AB, Richardson A, Ahima RS, et al: Rapamycin-induced insulin resistance is mediated by mTORC2 loss and uncoupled from longevity. Science 2012, 335:1638-1643.

22. Peterson TR, Laplante M, Thoreen CC, Sancak Y, Kang SA, Kuehl WM, Gray NS, Sabatini DM: DEPTOR is an mTOR inhibitor frequently overexpressed in multiple myeloma cells and required for their survival. Cell 2009, 137:873-886.

23. Hara K, Maruki Y, Long X, Yoshino K, Oshiro N, Hidayat S, Tokunaga C, Avruch J, Yonezawa K: Raptor, a binding partner of target of rapamycin (TOR), mediates TOR action. Cell 2002, 110:177-189.

24. Jastrzebski K, Hannan KM, Tchoubrieva EB, Hannan RD, Pearson RB: Coordinate regulation of ribosome biogenesis and function by the ribosomal protein $\mathrm{S} 6$ kinase, a key mediator of mTOR function. Growth Factors 2007, 25:209-226.

25. Bhandari BK, Feliers D, Duraisamy S, Stewart JL, Gingras AC, Abboud HE, Choudhury GG, Sonenberg N, Kasinath BS: Insulin regulation of protein translation repressor $4 \mathrm{E}-\mathrm{BP} 1$, an elF4E-binding protein, in renal epithelial cells. Kidney Int 2001, 59:866-875.

26. Jacinto E, Loewith R, Schmidt A, Lin S, Ruegg MA, Hall A, Hall MN: Mammalian TOR complex 2 controls the actin cytoskeleton and is rapamycin insensitive. Nat Cell Biol 2004, 6:1122-1128.

27. Rosner M, Fuchs C, Siegel N, Valli A, Hengstschlager M: Functional interaction of mammalian target of rapamycin complexes in regulating mammalian cell size and cell cycle. Hum Mol Genet 2009, 18:3298-3310.

28. Dada S, Demartines N, Dormond O: $\mathrm{mTORC2}$ regulates PGE2-mediated endothelial cell survival and migration. Biochem Biophys Res Commun 2008, 372:875-879.

29. Kumar A, Harris TE, Keller SR, Choi KM, Magnuson MA, Lawrence JC Jr: Muscle-specific deletion of rictor impairs insulin-stimulated glucose 
transport and enhances Basal glycogen synthase activity. Mol Cell Biol 2008, 28:61-70.

30. Sarbassov DD, Guertin DA, Ali SM, Sabatini DM: Phosphorylation and regulation of Akt/PKB by the rictor-mTOR complex. Science 2005, 307:1098-1101.

31. Frias MA, Thoreen CC, Jaffe JD, Schroder W, Sculley T, Carr SA, Sabatini DM: $\mathrm{mSin} 1$ is necessary for Akt/PKB phosphorylation, and its isoforms define three distinct mTORC2s. Curr Biol 2006, 16:1865-1870.

32. Jacinto E, Facchinetti V, Liu D, Soto N, Wei S, Jung SY, Huang Q, Qin J, Su B: SIN1/MIP1 maintains rictor-mTOR complex integrity and regulates Akt phosphorylation and substrate specificity. Cell 2006, 127:125-137.

33. Chen $\mathrm{CH}$, Sarbassov DD: The mTOR (mammalian target of rapamycin) kinase maintains integrity of mTOR complex 2. J Biol Chem 2011, 286:40386-40394.

34. Pearce LR, Huang X, Boudeau J, Pawlowski R, Wullschleger S, Deak M, Ibrahim AF, Gourlay R, Magnuson MA, Alessi DR: Identification of Protor as a novel Rictor-binding component of mTOR complex-2. Biochem J 2007, 405:513-522.

35. Pearce LR, Sommer EM, Sakamoto K, Wullschleger S, Alessi DR: Protor-1 is required for efficient $\mathrm{mTORC2}$-mediated activation of SGK1 in the kidney. Biochem J 2011, 436:169-179.

36. Hernandez-Negrete I, Carretero-Ortega J, Rosenfeldt H, Hernandez-Garcia R, Calderon-Salinas JV, Reyes-Cruz G, Gutkind JS, Vazquez-Prado J: P-Rex1 links mammalian target of rapamycin signaling to Rac activation and cell migration. J Biol Chem 2007, 282:23708-23715.

37. Sarbassov DD, Ali SM, Kim DH, Guertin DA, Latek RR, Erdjument-Bromage $H$, Tempst P, Sabatini DM: Rictor, a novel binding partner of mTOR, defines a rapamycin-insensitive and raptor-independent pathway that regulates the cytoskeleton. Curr Biol 2004, 14:1296-1302.

38. Gulhati P, Bowen KA, Liu J, Stevens PD, Rychahou PG, Chen M, Lee EY, Weiss $\mathrm{HL}, \mathrm{O}^{\prime}$ Connor KL, Gao T, Evers BM: mTORC1 and mTORC2 regulate EMT, motility, and metastasis of colorectal cancer via RhoA and Rac1 signaling pathways. Cancer Res 2011, 71:3246-3256.

39. Chan JC, Malik V, Jia W, Kadowaki T, Yajnik CS, Yoon KH, Hu FB: Diabetes in Asia: epidemiology, risk factors, and pathophysiology. Jama 2009, 301:2129-2140.

40. Maiese K, Chong ZZ, Shang YC: Mechanistic insights into diabetes mellitus and oxidative stress. Curr Med Chem 2007, 14:1729-1738.

41. Maiese K, Shang YC, Chong ZZ, Hou J: Diabetes mellitus: channeling care through cellular discovery. Curr Neurovasc Res 2010, 7:59-64

42. Melnik BC, John SM, Schmitz G: Over-stimulation of insulin/IGF-1 signaling by western diet may promote diseases of civilization: lessons learnt from laron syndrome. Nutr Metab (Lond) 2011, 8:41.

43. Harris Ml, Eastman RC: Early detection of undiagnosed diabetes mellitus: a US perspective. Diabetes Metab Res Rev 2000, 16:230-236.

44. Kurban S, Mehmetoglu I, Yerlikaya HF, Gonen S, Erdem S: Effect of chronic regular exercise on serum ischemia-modified albumin levels and oxidative stress in type 2 diabetes mellitus. Endocr Res 2011, 36:116-123.

45. Yang $H$, Jin X, Kei Lam CW, Yan SK: Oxidative stress and diabetes mellitus. Clin Chem Lab Med 2011, 49:1773-1782.

46. Daneman D: Type 1 diabetes. Lancet 2006, 367:847-858.

47. Maiese K, Chong ZZ, Shang YC, Hou J: Novel Avenues of Drug Discovery and Biomarkers for Diabetes Mellitus. J Clin Pharmacol 2011, 51:128-152.

48. Kernan WN, Inzucchi SE, Viscoli CM, Brass LM, Bravata DM, Horwitz RI: Insulin resistance and risk for stroke. Neurology 2002, 59:809-815.

49. Orchard TJ, Olson JC, Erbey JR, Williams K, Forrest KY, Smithline Kinder L, Ellis $D$, Becker DJ: Insulin resistance-related factors, but not glycemia, predict coronary artery disease in type 1 diabetes: 10-year follow-up data from the Pittsburgh Epidemiology of Diabetes Complications Study. Diabetes Care 2003, 26:1374-1379.

50. Maiese K, Chong ZZ, Shang YC, Hou J: FoxO proteins: cunning concepts and considerations for the cardiovascular system. Clin Sci (Lond) 2009, 116:191-203.

51. Reagan LP: Diabetes as a chronic metabolic stressor: causes, consequences and clinical complications. Exp Neurol 2012, 233:68-78.

52. Donath MY, Ehses JA, Maedler K, Schumann DM, Ellingsgaard H, Eppler E, Reinecke M: Mechanisms of beta-cell death in type 2 diabetes. Diabetes 2005, 54(Suppl 2):S108-113.

53. Maiese K, Hou J, Chong ZZ, Shang YC: Erythropoietin, forkhead proteins, and oxidative injury: biomarkers and biology. ScientificWorldJournal 2009 9:1072-1104.

54. Zengi A, Ercan G, Caglayan O, Tamsel S, Karadeniz M, Simsir I, Harman E, Kahraman C, Orman M, Cetinkalp S, Ozgen G: Increased oxidative DNA damage in lean normoglycemic offspring of type 2 diabetic patients. Exp Clin Endocrinol Diabetes 2011, 119:467-471.
55. Afanas'ev I: Signaling of reactive oxygen and nitrogen species in Diabetes mellitus. Oxid Med Cell Longev 2010, 3:361-373.

56. Maiese K, Li F, Chong ZZ: New avenues of exploration for erythropoietin. Jama 2005, 293:90-95.

57. Chong ZZ, Shang YC, Maiese K: Vascular injury during elevated glucose can be mitigated by erythropoietin and Wnt signaling. Curr Neurovasc Res 2007, 4:194-204

58. Gaddini L, Villa M, Matteucci A, Mallozzi C, Petrucci TC, Di Stasi AM, Leo L, Malchiodi-Albedi F, Pricci F: Early effects of high glucose in retinal tissue cultures Renin-Angiotensin system-dependent and -independent signaling. Neurobiol Dis 2009, 35:278-285.

59. Hou J, Chong ZZ, Shang YC, Maiese K: FoxO3a governs early and late apoptotic endothelial programs during elevated glucose through mitochondrial and caspase signaling. Mol Cell Endocrinol 2010, 321:194-206.

60. Gossai D, Lau-Cam CA: The effects of taurine, taurine homologs and hypotaurine on cell and membrane antioxidative system alterations caused by type 2 diabetes in rat erythrocytes. Adv Exp Med Biol 2009, 643:359-368.

61. Singh DK, Winocour P, Farrington K: Mechanisms of disease: the hypoxic tubular hypothesis of diabetic nephropathy. Nat Clin Pract Nephrol 2008, 4:216-226.

62. Barbosa NB, Oliveira C, Araldi D, Folmer V, Rocha JB, Nogueira CW: Acute diphenyl diselenide treatment reduces hyperglycemia but does not change delta-aminolevulinate dehydratase activity in alloxan-induced diabetes in rats. Biol Pharm Bull 2008, 31:2200-2204.

63. Maiese K, Chong ZZ, Shang YC: OutFOXOing disease and disability: the therapeutic potential of targeting FoxO proteins. Trends Mol Med 2008, $14: 219-227$

64. Chong ZZ, Hou J, Shang YC, Wang S, Maiese K: EPO Relies upon Novel Signaling of Wnt1 that Requires Akt1, FoxO3a, GSK-3beta, and beta-Catenin to Foster Vascular Integrity During Experimental Diabetes. Curr Neurovasc Res 2011, 8:103-120.

65. Hou J, Chong ZZ, Shang YC, Maiese K: Early apoptotic vascular signaling is determined by Sirt1 through nuclear shuttling, forkhead trafficking, bad, and mitochondrial caspase activation. Curr Neurovasc Res 2010, 7:95-112.

66. Szabo C: Role of nitrosative stress in the pathogenesis of diabetic vascular dysfunction. Br J Pharmacol 2009, 156:713-727.

67. Ceriello A, dello Russo P, Amstad P, Cerutti P: High glucose induces antioxidant enzymes in human endothelial cells in culture. Evidence linking hyperglycemia and oxidative stress. Diabetes 1996, 45:471-477.

68. Valle I, Alvarez-Barrientos A, Arza E, Lamas S, Monsalve M: PGC-1alpha regulates the mitochondrial antioxidant defense system in vascular endothelial cells. Cardiovasc Res 2005, 66:562-573.

69. Chong ZZ, Kang JQ, Maiese K: Erythropoietin is a novel vascular protectant through activation of Akt1 and mitochondrial modulation of cysteine proteases. Circulation 2002, 106:2973-2979.

70. Li Y, Wu H, Khardori R, Song YH, Lu YW, Geng YJ: Insulin-like growth factor-1 receptor activation prevents high glucose-induced mitochondrial dysfunction, cytochrome-c release and apoptosis. Biochem Biophys Res Commun 2009, 384:259-264.

71. Alexandru N, Popov D, Georgescu A: Platelet dysfunction in vascular pathologies and how can it be treated. Thromb Res 2012, 129:116-126.

72. Donahoe SM, Stewart GC, McCabe CH, Mohanavelu S, Murphy SA, Cannon $C P$, Antman EM: Diabetes and mortality following acute coronary syndromes. JAMA 2007, 298:765-775.

73. Thackeray JT, Radziuk J, Harper ME, Suuronen EJ, Ascah KJ, Beanlands RS, Dasilva JN: Sympathetic nervous dysregulation in the absence of systolic left ventricular dysfunction in a rat model of insulin resistance with hyperglycemia. Cardiovasc Diabetol 2011, 10:75.

74. Maiese K, Chong ZZ, Hou J, Shang YC: The vitamin nicotinamide: translating nutrition into clinical care. Molecules 2009, 14:3446-3485.

75. Monnier L, Mas E, Ginet C, Michel F, Villon L, Cristol JP, Colette C: Activation of oxidative stress by acute glucose fluctuations compared with sustained chronic hyperglycemia in patients with type 2 diabetes. JAMA 2006, 295:1681-1687.

76. Estep PW, Warner JB, Bulyk ML: Short-term calorie restriction in male mice feminizes gene expression and alters key regulators of conserved aging regulatory pathways. PLOS One 2009, 4:e5242.

77. Chong ZZ, Shang YC, Wang S, Maiese K: SIRT1: New avenues of discovery for disorders of oxidative stress. Expert Opin Ther Targets 2012, 16:167-178. 
78. Herranz D, Serrano M: SIRT1: recent lessons from mouse models. Nat Rev Cancer 2010, 10:819-823.

79. Kelly GS: A review of the sirtuin system, its clinical implications, and the potential role of dietary activators like resveratrol: part 2. Altern Med Rev 2010, 15:313-328.

80. Maiese K, Chong ZZ, Shang YC, Wang S: Translating cell survival and cell longevity into treatment strategies with SIRT1. Rom J Morphol Embryol 2011, 52:1173-1185.

81. Orimo M, Minamino T, Miyauchi H, Tateno K, Okada S, Moriya J, Komuro I: Protective role of SIRT1 in diabetic vascular dysfunction. Arterioscler Thromb Vasc Biol 2009, 29:889-894.

82. Zhang QJ, Wang Z, Chen HZ, Zhou S, Zheng W, Liu G, Wei YS, Cai H, Liu DP, Liang CC: Endothelium-specific overexpression of class III deacetylase SIRT1 decreases atherosclerosis in apolipoprotein E-deficient mice. Cardiovasc Res 2008, 80:191-199.

83. Tanno M, Kuno A, Yano T, Miura T, Hisahara S, Ishikawa S, Shimamoto K, Horio $Y$ : Induction of manganese superoxide dismutase by nuclear translocation and activation of SIRT1 promotes cell survival in chronic heart failure. J Biol Chem 2010, 285:8375-8382.

84. Kume S, Haneda M, Kanasaki K, Sugimoto T, Araki S, Isono M, Isshiki K, Uzu T, Kashiwagi A, Koya D: Silent information regulator 2 (SIRT1) attenuates oxidative stress-induced mesangial cell apoptosis via p53 deacetylation. Free Radic Biol Med 2006, 40:2175-2182.

85. Hou J, Wang S, Shang YC, Chong ZZ, Maiese K: Erythropoietin Employs Cell Longevity Pathways of SIRT1 to Foster Endothelial Vascular Integrity During Oxidant Stress. Curr Neurovasc Res 2011, 8:220-235.

86. Alcendor RR, Gao S, Zhai P, Zablocki D, Holle E, Yu X, Tian B, Wagner T, Vatner SF, Sadoshima J: Sirt1 regulates aging and resistance to oxidative stress in the heart. Circ Res 2007, 100:1512-1521.

87. Wang RH, Kim HS, Xiao C, Xu X, Gavrilova O, Deng CX: Hepatic Sirt1 deficiency in mice impairs mTorc2/Akt signaling and results in hyperglycemia, oxidative damage, and insulin resistance. J Clin Invest 2011, 121:4477-4490

88. Guo W, Qian L, Zhang J, Zhang W, Morrison A, Hayes P, Wilson S, Chen T, Zhao J: Sirt1 overexpression in neurons promotes neurite outgrowth and cell survival through inhibition of the mTOR signaling. J Neurosci Res 2011, 89:1723-1736.

89. Harrison DE, Strong R, Sharp ZD, Nelson JF, Astle CM, Flurkey K, Nadon NL, Wilkinson JE, Frenkel K, Carter CS, et al: Rapamycin fed late in life extends lifespan in genetically heterogeneous mice. Nature 2009, 460:392-395.

90. Selman C, Tullet JM, Wieser D, Irvine E, Lingard SJ, Choudhury Al, Claret M, Al-Qassab H, Carmignac D, Ramadani F, et al: Ribosomal protein S6 kinase 1 signaling regulates mammalian life span. Science 2009, 326:140-144.

91. Anisimov VN, Zabezhinski MA, Popovich IG, Piskunova TS, Semenchenko AV, Tyndyk ML, Yurova MN, Antoch MP, Blagosklonny MV: Rapamycin extends maximal lifespan in cancer-prone mice. Am J Pathol 2010, 176:2092-2097.

92. Pende M, Kozma SC, Jaquet M, Oorschot V, Burcelin R, Le Marchand-Bruste Y, Klumperman J, Thorens B, Thomas G: Hypoinsulinaemia, glucose intolerance and diminished beta-cell size in S6K1-deficient mice. Nature 2000, 408:994-997

93. Hamada S, Hara K, Hamada T, Yasuda H, Moriyama H, Nakayama R, Nagata $\mathrm{M}$, Yokono K: Upregulation of the mammalian target of rapamycin complex 1 pathway by Ras homolog enriched in brain in pancreatic beta-cells leads to increased beta-cell mass and prevention of hyperglycemia. Diabetes 2009, 58:1321-1332.

94. Fraenkel M, Ketzinel-Gilad M, Ariav Y, Pappo O, Karaca M, Castel J, Berthault MF, Magnan C, Cerasi E, Kaiser N, Leibowitz G: mTOR inhibition by rapamycin prevents beta-cell adaptation to hyperglycemia and exacerbates the metabolic state in type 2 diabetes. Diabetes 2008, 57:945-957.

95. Deblon N, Bourgoin L, Veyrat-Durebex C, Peyrou M, Vinciguerra M, Caillon A, Maeder C, Fournier M, Montet X, Rohner-Jeanrenaud F, Foti M: Chronic mTOR inhibition by rapamycin induces muscle insulin resistance despite weight loss in rats. Br J Pharmacol 2012, 165:2325-2340

96. Harrington LS, Findlay GM, Gray A, Tolkacheva T, Wigfield S, Rebholz H, Barnett J, Leslie NR, Cheng S, Shepherd PR, et al: The TSC1-2 tumor suppressor controls insulin-PI3K signaling via regulation of IRS proteins. $J$ Cell Biol 2004, 166:213-223.

97. Khamzina L, Veilleux A, Bergeron S, Marette A: Increased activation of the mammalian target of rapamycin pathway in liver and skeletal muscle of obese rats: possible involvement in obesity-linked insulin resistance. Endocrinology 2005, 146:1473-1481.
98. Kim JA, Jang HJ, Martinez-Lemus LA, Sowers JR: Activation of mTOR/p70S6 Kinase by ANG II Inhibits Insulin Stimulated Endothelial Nitric Oxide Synthase and Vasodilation. Am J Physiol Endocrinol Metab 2012, 302:E201-208.

99. Inoki K, Zhu T, Guan KL: TSC2 mediates cellular energy response to control cell growth and survival. Cell 2003, 115:577-590.

100. Paiva MA, Rutter-Locher Z, Goncalves LM, Providencia LA, Davidson SM, Yellon DM, Mocanu MM: Enhancing AMPK activation during ischemia protects the diabetic heart against reperfusion injury. Am J Physiol Heart Circ Physiol 2011, 300:H2123-2134

101. Saha AK, Xu XJ, Lawson E, Deoliveira R, Brandon AE, Kraegen EW, Ruderman NB: Downregulation of AMPK accompanies leucine- and glucose-induced increases in protein synthesis and insulin resistance in rat skeletal muscle. Diabetes 2010, 59:2426-2434.

102. Shaw RJ, Kosmatka M, Bardeesy N, Hurley RL, Witters LA, DePinho RA, Cantley LC: The tumor suppressor LKB1 kinase directly activates AMPactivated kinase and regulates apoptosis in response to energy stress. Proc Natl Acad Sci U S A 2004, 101:3329-3335.

103. Jessen N, Koh HJ, Folmes CD, Wagg C, Fujii N, Lofgren B, Wolf CM, Berul Cl, Hirshman MF, Lopaschuk GD, Goodyear LJ: Ablation of LKB1 in the heart leads to energy deprivation and impaired cardiac function. Biochim Biophys Acta 2010, 1802:593-600.

104. Steppan CM, Bailey ST, Bhat S, Brown EJ, Banerjee RR, Wright CM, Patel HR, Ahima RS, Lazar MA: The hormone resistin links obesity to diabetes. Nature 2001, 409:307-312.

105. Kang S, Chemaly ER, Hajjar RJ, Lebeche D: Resistin promotes cardiac hypertrophy via the AMP-activated protein kinase/mammalian target of rapamycin (AMPK/mTOR) and c-Jun N-terminal kinase/insulin receptor substrate 1 (JNK/IRS1) pathways. J Biol Chem 2011, 286:18465-18473.

106. Shan J, Nguyen TB, Totary-Jain H, Dansky H, Marx SO, Marks AR: Leptin-enhanced neointimal hyperplasia is reduced by mTOR and PI3K inhibitors. Proc Natl Acad Sci U S A 2008, 105:19006-19011.

107. Pasini E, Flati V, Paiardi S, Rizzoni D, Porteri E, Aquilani R, Assanelli D, Corsetti G, Speca S, Rezzani R, et al: Intracellular molecular effects of insulin resistance in patients with metabolic syndrome. Cardiovasc Diabetol 2010, 9:46.

108. Medeiros C, Frederico MJ, da Luz G, Pauli JR, Silva AS, Pinho RA, Velloso LA Ropelle ER, De Souza CT: Exercise training reduces insulin resistance and upregulates the mTOR/p70S6k pathway in cardiac muscle of dietinduced obesity rats. J Cell Physio/ 2011, 226:666-674.

109. Wang B, Atherton P, Patel R, Manning G, Donnelly R: Antiangiogenic effects and transcriptional regulation of pigment epithelium-derived factor in diabetic retinopathy. Microvasc Res 2010, 80:31-36.

110. Xue Q, Nagy JA, Manseau EJ, Phung TL, Dvorak HF, Benjamin LE: Rapamycin inhibition of the Akt/mTOR pathway blocks select stages of VEGF-A164-driven angiogenesis, in part by blocking S6Kinase. Arterioscler Thromb Vasc Biol 2009, 29:1172-1178.

111. Roulin D, Cerantola Y, Dormond-Meuwly A, Demartines N, Dormond O: Targeting mTORC2 inhibits colon cancer cell proliferation in vitro and tumor formation in vivo. Mol Cancer 2010, 9:57.

112. Chong ZZ, Li F, Maiese K: The pro-survival pathways of mTOR and protein kinase $B$ target glycogen synthase kinase-3beta and nuclear factor-kappaB to foster endogenous microglial cell protection. Int J Mol Med 2007, 19:263-272.

113. Dello Russo C, Lisi L, Tringali G, Navarra P: Involvement of mTOR kinase in cytokine-dependent microglial activation and cell proliferation. Biochem Pharmacol 2009, 78:1242-1251.

114. Poulose SM, Bielinski DF, Carrihill-Knoll K, Rabin BM, Shukitt-Hale B: Exposure to (16)O-Particle Radiation Causes Aging-Like Decrements in Rats through Increased Oxidative Stress, Inflammation and Loss of Autophagy. Radiat Res 2011, 176:761-769.

115. Shang YC, Chong ZZ, Wang S, Maiese K: Erythropoietin and Wnt1 Govern Pathways of mTOR, Apaf-1, and XIAP in Inflammatory Microglia. Curr Neurovasc Res 2011, 8:270-285.

116. Shang YC, Chong ZZ, Wang S, Maiese K: Prevention of beta-amyloid degeneration of microglia by erythropoietin depends on Wnt1, the PI 3-K/mTOR pathway, Bad, and Bcl-xL. Aging (Albany NY) 2012, 4:187-201.

doi:10.1186/1475-2840-11-45

Cite this article as: Chong and Maiese: Mammalian target of rapamycin signaling in diabetic cardiovascular disease. Cardiovascular Diabetology 2012 11:45 